\title{
Effect of Friction Stir Process Parameters on Mechanical Properties of Al/Eggshell/SiC Composite Material
}

\author{
Anas Islam $^{1 *}$, Vijay K. Dwivedi ${ }^{1}$, Shashi Prakash Dwivedi ${ }^{2}$ \\ ${ }^{1}$ Department of Mechanical Engineering, IET, GLA University, Mathura, U.P. 281406, India \\ ${ }^{2}$ G. L. Bajaj Institute of Technology \& Management, Greater Noida, Gautam Buddha Nagar, U.P. 201310, India
}

Corresponding Author Email: shashi.dwivedi@glbitm.ac.in

https://doi.org/10.18280/acsm.450107

Received: 26 November 2020

Accepted: 1 February 2021

\section{Keywords:}

composite, MMC, FSP, Box-Behnken Design, mechanical properties, hardness, tensile strength, ball-milling

\begin{abstract}
The rise in pollution is a serious matter of concern for all nations. Industries are mainly responsible for damaging the balance of the cycle of pollution. In this paper, the mechanical properties of Aluminum have been enhanced by reinforcing it with eggshell wastes and $\mathrm{SiC}$ as reinforcement particles. Ball-milling technique has been applied for up to 75 hours for making the densities of Aluminum, Eggshell and $\mathrm{SiC}$ equal. The prime focus of this work is to improve the hardness value of Aluminium-based final composite material. Friction Stir Process (FSP) technique has been used to develop the composite and the driving parameters of FSP like rotational speed, transverse speed etc. are optimized with the help of the Box-Behnken Design approach. The optimized value of rotation speed was $966.14 \mathrm{rpm}$ as well as transverse speed was $23.18 \mathrm{~mm} / \mathrm{min}$. Hardness and tensile strength of composite developed at an optimum combination of parameters were found to be $72.2 \mathrm{BHN}$ and $194.48 \mathrm{MPa}$ respectively. Results showed that tensile strength and hardness were enhanced by about $44.05 \%$ and $64.09 \%$ respectively.
\end{abstract}

\section{INTRODUCTION}

Rise in pollution at such an alarming rate has not only disturbed the ecological system but also played its role well in damaging the health of living beings to a great extent. In recent years it has made its significant place in the list of one of the most damaging factors for a nation and thus it turns out to be a major dent for a country [1]. With the rapid growth of population especially in developing countries like India, the demands are also increasing and this fact cannot be denied that industries play a crucial role in fulfilling the needs and demands. In this new age of science \& Technology, one cannot even think to not consume the industrial goods [2]. On one hand, industries are an important player in the development of a nation and on the other hand they are potentially very harmful to living beings due to the wastes that are generated by them. The only way to combat from it is to find new ways for the proper treatment of such wastes and the most suitable one is recycling [3]. There are many benefits of recycling the wastes some of them are less pollution, conservation of natural resources which are replenishing very fastly and of course there would be less investment of capital [4].

Industries that one can think of while the issues of pollution are being discussed are leather industries, automobile industries and other small vendors etc. It is quite surprising that the wastes created by food industries have not attained that much limelight, although such kind of food wastes is a best suitable habitat for the growth of deadly viruses and bacteria that may enter to the human body via nose or mouth and can cause various types of illnesses [5-7]. Egg consumption is very common in hotels, food processing industries and other related places also the shell of the egg (waste eggshell) is thrown as garbage and no further processing of eggshell wastes is done thus, they create a lot of environmental pollution. It is well known that eggshell consists of calcium carbonate which is a hard phased material thus it could be used as a reinforcement particle to enhance the mechanical properties of any base material [1].

$\mathrm{Al}$ is a very common element that is present about $8 \%$ of the total earth's crust it is having certain various important properties that is why it is used most abundantly after steel. According to the latest report it is found that the demand of Aluminum is approximately 29 million per year. The reason behind this high demand of $\mathrm{Al}$ is its unmatched properties like lightweight, corrosion-resistant, higher electrical conductance etc. The usage of $\mathrm{Al}$ is not confined only for certain applications but it is being used widely in simpler items like food packaging foils, to the most complicated ones like automobile industries, aerospace and for defense types of equipment [8]. The pure form of Aluminum is soft and ductile therefore it is required to increase its mechanical properties like hardness and tensile strength. Alloying and reinforcement is a very common practice to enhance the properties of $\mathrm{Al}$ and make this element suitable for various applications [9].

Silicon carbide is the only known carbon and silicon-based compound. It was first developed by an electrochemical reaction of carbon and sand at the high-temperature range. Silicon Carbide is a very good abrasive material and has been in wide usage since ages in grinding wheels and other abrasive goods. SiC is often being used in several other industries like refractories, ceramics etc. This compound could also be converted into an "electrical conductor" and has uses in thermal resistance, flame steam generators and electrical devices. Applications for the structure and wear are continuously evolving. The major qualities of $\mathrm{SiC}$ are the lower value of density, higher strength, the high value of 
hardness, excellent chemical inertness etc. [10].

In this paper, the properties (Hardness and Tensile strength) of Aluminum have been enhanced by reinforcing it with eggshell wastes and $\mathrm{SiC}$ as reinforcement particles. As the densities of $\mathrm{SiC}$ and eggshells possess different values thus ball milling technique has been used for approximately 75 hours to make their densities equal. The prime focus of this work is to improve the hardness value of Aluminium-based final composite material. Friction Stir Process (FSP) technique has been used to develop the composite and the driving parameters of FSP like rotational speed, transverse speed etc. are optimized with the help of the Box-Behnken Design approach.

\section{INVESTIGATED MATERIALS EXPERIMENTAL METHODS}

\subsection{Formation of eggshell powder from waste eggshell and its ball-milling}

Eggshell is a type of industrial wastes that is available easily, a few of such eggshells were collected. A typical eggshell generally contains $95 \%$ of $\mathrm{CaCO}_{3}$ in the form of calcites which is considered to be a hard phased compound the other constituting elements include organic materials like $\mathrm{Al}_{2} \mathrm{O}_{3}$, $\mathrm{SiO}_{2}$, Sulphur, Phosphorus, Calcium, $\mathrm{Cr}_{2} \mathrm{O}_{3}, \mathrm{MnO}$ and few other proteins.

These collected eggshells were properly washed with water then they are allowed to dry in the sunlight. To obtain its powdered form these sundried eggshells were subjected to ball-mill. After ball milling, these powdered forms of eggshells are ready to be utilized as a primary reinforcement particle to develop Aluminium-based composite [1]. Figure 1 illustrates the formation of carbonized eggshells from the waste eggshells. Table 1 summarizes the chemical composition of a typical eggshell.

Table 1. Chemical composition of a typical egg shell

\begin{tabular}{cc}
\hline Element available in ES & Value\% \\
\hline (Calcium oxide) $\mathrm{CaO}$ & 50.70 \\
(Silicon dioxide) $\mathrm{SiO}_{2}$ & 0.09 \\
(Aluminum oxide) $\mathrm{Al}_{2} \mathrm{O}_{3}$ & 0.03 \\
(Ferric oxide) $\mathrm{Fe}_{2} \mathrm{O}_{3}$ & 0.02 \\
(Magnesium oxide) $\mathrm{MgO}$ & 0.01 \\
(Sodium oxide) $\mathrm{Na}_{2} \mathrm{O}$ & 0.19 \\
(Strontium oxide) $\mathrm{SrO}$ & 0.13 \\
(Nickel oxide) $\mathrm{NiO}$ & 0.001 \\
(Phosphorus oxide) $\mathrm{P}_{2} \mathrm{O}_{5}$ & 0.24 \\
(Sulphur oxide) $\mathrm{SO}_{3}$ & 0.55 \\
(Chlorine) $\mathrm{Cl}$ & 0.08 \\
(Loss of ignition) $\mathrm{LOI}$ & 47.80 \\
\hline
\end{tabular}

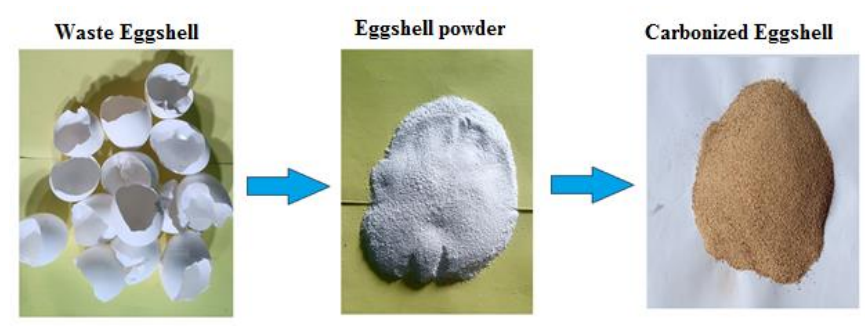

Figure 1.Waste eggshell and its formation in carbonized eggshell powder

\subsection{Experimental procedure}

In the present study, the aluminium based plate used to develop the surface composite using Eggshell and $\mathrm{SiC}$ reinforcement particles. Hardness and tensile strength of the base plate were $44 \mathrm{BHN}$ and $135 \mathrm{MPa}$. The dimensions of the plates taken were $100 \mathrm{~mm} \times 50 \mathrm{~mm} \times 10 \mathrm{~mm}$. A groove of 1 $\mathrm{mm}$ width and $3 \mathrm{~mm}$ depth was made in the aluminium plate with the help of a vertical milling machine [11]. Figure 2 illustrates the schematic representation of FSP process and the development of composite. The FSP process parameters with their ranges are shown in Table 2. Design matrix for Hardness is shown in Table 3. Figure 2 shows the process to develop the composite.

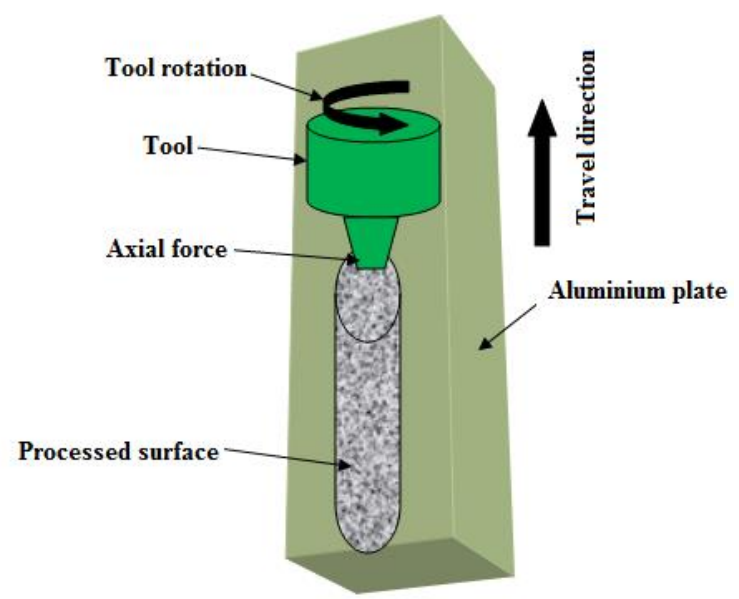

Figure 2. Development of hybrid composite material using friction stir process

Table 2. The FSP parameters with their ranges

\begin{tabular}{ccc}
\hline S.No. & Process parameters & Ranges \\
\hline 1 & Number of tool pass & $1-3$ \\
2 & Tool rotational speed (rpm) & $800-1000$ \\
3 & Transverse Speed (mm/min) & $15-25$ \\
\hline
\end{tabular}

Table 3. Design matrix table

\begin{tabular}{cccccc}
\hline Standard order & Run & A: Number of tool pass & B: Rotational Speed (rpm) & C: Transverse Speed (mm/min) & Hardness (BHN) \\
\hline 4 & 1 & 3 & 1000 & 20 & 62.41 \\
16 & 2 & 2 & 900 & 20 & 69.95 \\
8 & 3 & 3 & 900 & 25 & 68.35 \\
9 & 4 & 2 & 800 & 20 & 61.64 \\
17 & 5 & 2 & 900 & 20 & 69.98 \\
1 & 6 & 1 & 800 & 15 & 51.01 \\
6 & 7 & 3 & 900 & 20 & 64.44 \\
2 & 8 & 3 & 800 & 25 & 68.05 \\
11 & 9 & 2 & 800 & & \\
\end{tabular}




\begin{tabular}{|c|c|c|c|c|c|}
\hline 12 & 10 & 2 & 1000 & 25 & 69.5 \\
\hline 15 & 11 & 2 & 900 & 20 & 69.92 \\
\hline 7 & 12 & 1 & 900 & 25 & 74.95 \\
\hline 10 & 13 & 2 & 1000 & 15 & 59.66 \\
\hline 13 & 14 & 2 & 900 & 20 & 69.95 \\
\hline 5 & 15 & 1 & 900 & 15 & 68.5 \\
\hline 14 & 16 & 2 & 900 & 20 & 69.86 \\
\hline 3 & 17 & 1 & 1000 & 20 & 72.87 \\
\hline 4 & 1 & 3 & 1000 & 20 & 62.41 \\
\hline
\end{tabular}

Table 4. ANOVA table

\begin{tabular}{ccccccc}
\hline Source & Sum of Squares & DF & MeanSquare & F Value & Prob > F & \\
\hline Model & 342.9077215 & 9 & 38.10085794 & 27063.01427 & $<0.0001$ & Significant \\
A & 138.6945125 & 1 & 138.6945125 & 98514.62075 & $<0.0001$ & \\
B & 0.1458 & 1 & 0.1458 & 103.5616438 & $<0.0001$ & \\
C & 132.9265125 & 1 & 132.9265125 & 94417.61416 & $<0.0001$ & \\
A2 & 0.505525263 & 1 & 0.505525263 & 359.074261 & $<0.0001$ & \\
B2 & 26.33684632 & 1 & 26.33684632 & 18707.04457 & $<0.0001$ & \\
C2 & 31.16880947 & 1 & 31.11680947 & 22102.24925 & $<0.0001$ & \\
AB & 4.558225 & 1 & 4.558225 & 3237.704211 & $<0.0001$ & \\
AC & 2.9929 & 1 & 2.9929 & 2125.854896 & $<0.0001$ & \\
BC & 2.941225 & 1 & 2.941225 & 2089.150178 & $<0.0001$ & \\
Residual & 0.009855 & 7 & 0.001407857 & & & \\
Lack of Fit & 0.001575 & 3 & 0.000525 & 0.253623188 & 0.8556 & Not significant \\
Pure Error & 0.00828 & 4 & 0.00207 & & & \\
Cor Total & 342.9175765 & 16 & & & & \\
Std. Dev. & 0.037521422 & R-Squared & 0.999971261 & & & \\
Mean & 67.63882353 & Adj R-Squared & 0.999934312 & & & \\
C.V. & 0.055473204 & Pred R-Squared & 0.999888785 & & & \\
PRESS & 0.0381375 & Adeq Precision & 572.6672851 & & & \\
\hline \multicolumn{7}{c}{}
\end{tabular}

\section{RESULTS AND DISCUSSION}

\subsection{Mathematical modeling}

Table 4 represents the ANOVA table. The modeling of the response surface is given by the Box-Behnken experimental designs. Such models are not based on total or FEM models. The layout nodes are located in the center of $\mathrm{k}-1$ section subdomains. For example, as in case of three variables, the parameters are set in the center of the empirical domain's limits. Three components each variable is required in all of these models. The three-factor Box-Behnken architecture doesn't really act in accordance with the iso-variance per revolution requirements. That being said, if functional block become incorporated, the prototypes described, with over three variables, will fulfill the iso-variance criterion. The orthogonality criterion could also be complied with by such layouts. The Box-Behnken models make it much easier to consecutively analyze the influence of different design parameters unless the other parameters are held at a stable value throughout the research of first indicators. Current analysis has been performed to optimize the FSP parameters by using the approach of Box Behnken design. It is quite evident from the ANOVA table that all the FSP parameters are significant, whereas lack of fit corresponds to non-significant values. The significant parameters signify that they have a full effect on the response i.e., Hardness and Tensile strength. Model is significant could be well said by observing the model F-value which came out to be 7386.96 . There is only $0.001 \%$ probability that noise could be able to create a larger value of Model-F. Value of "prob $>$ F" less than 0.0500 implies that the terms of the model are significant. In case A, B, C, A2, B2, C2, $\mathrm{AB}, \mathrm{AC}, \mathrm{BC}$ are all significant model terms. Those values which are greater than 0.1000 implies that the terms of the model are non-significant, also the parameters are affecting the responses quite well. The "Pred R- Squared" of 0.9999 and "Adj R- Squared" of 0.9999 are in a reasonable agreement to each other. $\mathrm{S} / \mathrm{N}$ ratio (signal to noise) has been evaluated by "Adeq Precision". Value of the ration greater than 4 is preferable the Adeq precision value of 572.66 corresponds to the adequacy of the signals. In order to navigate the space of design, this model works well. The relationship between hardness and input parameters has been shown by Eq. (1).

$$
\begin{aligned}
& \text { Hardness }=-162.94650+0.59775 \times \mathrm{N}_{\mathrm{TP}}+0.43588 \times \\
& \omega+3.27535 \times \mathrm{T}_{\mathrm{s}}+0.34650 \times \mathrm{N}_{\mathrm{TP}}{ }^{2}-2.50100 \mathrm{E}-004 \times \omega^{2} \\
& -0.10874 \times \mathrm{T}_{\mathrm{s}}{ }^{2}-0.010675 \times \mathrm{N}_{\mathrm{TP}} \times \mathrm{T}_{\mathrm{s}}+0.17300 \times \\
& \mathrm{N}_{\mathrm{TP}} \times \mathrm{T}_{\mathrm{s}}+1.71500 \mathrm{E}-003 \times \omega \times \mathrm{T}_{\mathrm{s}}
\end{aligned}
$$

where, $\mathrm{N}_{\mathrm{TP}}=$ Number of tool pass, $\omega=$ Rotational Speed and $\mathrm{T}_{\mathrm{s}}=$ Transverse Speed.

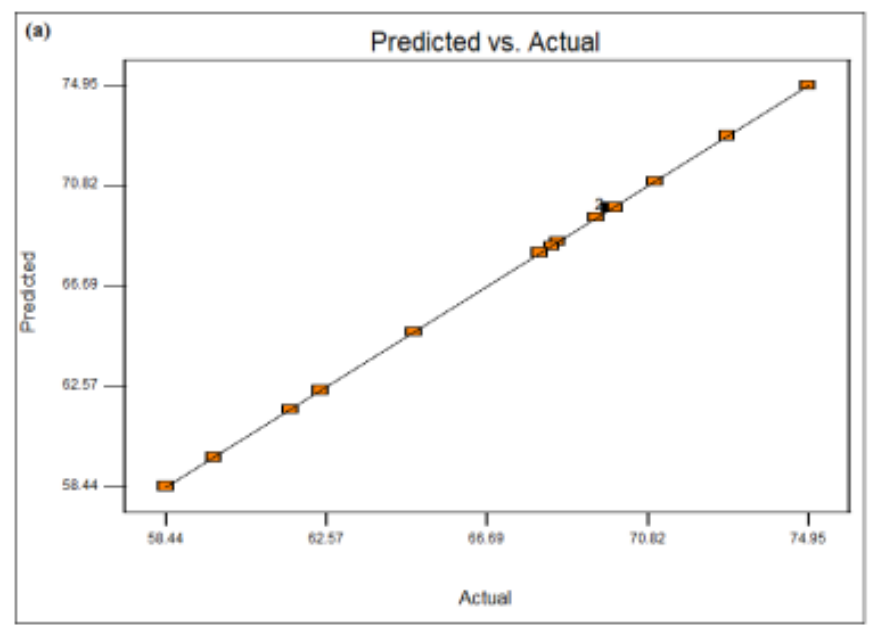




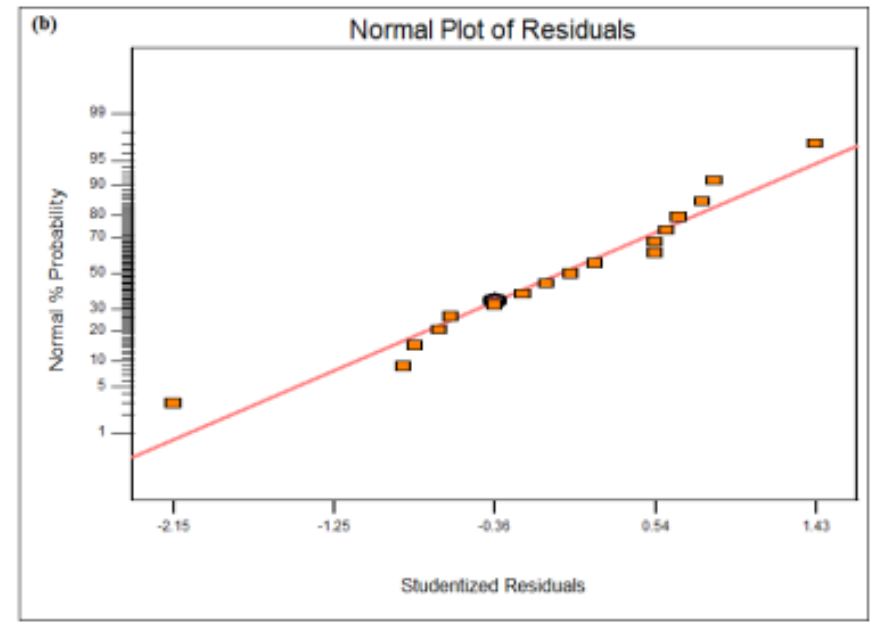

Figure 3. Model graph; (a) Predicted v/s actual, (b) Normal\% probability graph
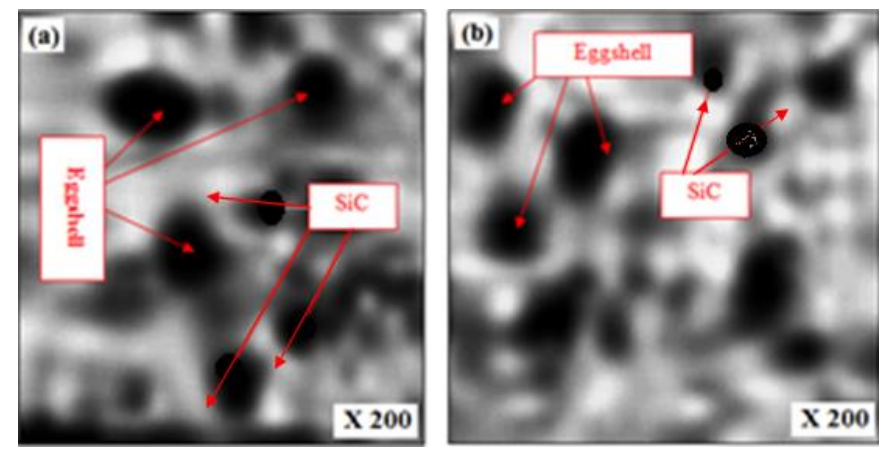

Figure 4. Microstructure images of green hybrid composite at $966.14 \mathrm{rpm}$ (a) before FSP (b) After FSP

The comparison between the predicted and actual values has been shown in Figure 3 through the graphs of percentage probability. The graph characteristics indicate that both of these graphs are following a straight-line pattern.

\subsection{Microstructural investigation at optimum FSP parameters}

It is necessary to know if reinforcement particles are well dispersed inside the matrices for observing the microstructure image of the composite. When the "matrix material" blends well the reinforcement particles then the mechanical properties of the matrix material improve well. In particular, tensile strength and hardness increase well. Although the mechanical properties of the base material would not have developed well if the reinforcement particles were not well distributed in the matrix material [12-14]. Figure 4 shows the surface composite microstructure picture formed at optimum FSP parameters (with a single pass by placing the device rotational speed and transverse speed at approximately $966.14 \mathrm{rpm}$ and approximately $23.18 \mathrm{~mm} / \mathrm{min}$, respectively). It was noticed that the distribution of reinforcement particles was strong when the composite was designed to optimum parameters.

\subsection{Hardness analysis}

\subsubsection{Effect of number of pass on hardness}

Figure 5 showed the impact of the tool pass on hardness. The value of hardness was the highest when the composite was generated by one tool transfer. Nevertheless, the hardness was the lowest when the composite was formed by the three-pass passing method [15-17]. The fine grain structure is accomplished in a single pass [12]. Fine-grain aims to promote the hardness of the composite.

\subsubsection{Effect of Tool Rotational Speed on Hardness}

The association of the tool speed with hardness is shown in Figure 5. For the chosen set of process parameters, ultimate hardness was defined at 966.14 devices rotational speed. Therefore, the tool rotation speed was not understood to be too high or too low by looking at the chart [18-20].

\subsubsection{Effect of Transverse Speed on Hardness}

When transverse speed increases, the hardness continuously increases. At $23.18 \mathrm{~mm} / \mathrm{min}$, the maximum hardness was achieved. Transverse speed effects on the hardness are shown in Figure 5. Increased transverse speed contributed to an improvement of the composite grain structure, which contributed to a significant rise in the composite mechanical properties [21-23].

\subsubsection{Confirmation Experiment}

Figure 6 illustrates the graph of ramp function. Ramp function graph is used to find the optimized parameters of FSP.

The ramp function is defined by:

$$
\begin{gathered}
x H(x) \\
\int_{-\infty}^{x} H\left(x^{\prime}\right) d x^{\prime} \\
\int_{-\infty}^{\infty} H\left(x^{\prime}\right) H\left(x-x^{\prime}\right) d x^{\prime} \\
H(x) * H(x),
\end{gathered}
$$

where is the Heaviside step function and denotes convolution. It is implemented in the Wolfram Language as Ramp[x]. The derivative is:

$$
R^{\prime}(x)=H(x)
$$

The Fourier transform of the ramp function is given by Pai:

$$
\begin{gathered}
\int_{-\infty}^{\infty} e^{-2 \pi i k x} R(x) d x \\
\frac{i \delta^{\prime}(k)}{4 \pi}-\frac{1}{4 \pi^{2} k^{2}}
\end{gathered}
$$

where, $\delta(x)$ is the delta function and $\delta^{\prime}(x)$ its derivative.

From the ramp function, it could be well said that the optimal value of hardness must be $74.99 \mathrm{BHN}$, when rotational speed and transverse speed were $966.14 \mathrm{rpm}$ and 23.18 $\mathrm{mm} / \mathrm{min}$ respectively with single tool pass. Confirmation experiment was carried out at an optimum combination of FSP parameters. Hardness was found to be $72.2 \mathrm{BHN}$. Mathematical modelling results show that the error was only $3.72 \%$ this is acceptable. Tensile strength was also identified at the optimum combination of FSP parameters. Tensile strength of composite developed at an optimum combination of parameters was found to $194.48 \mathrm{MPa}$. 

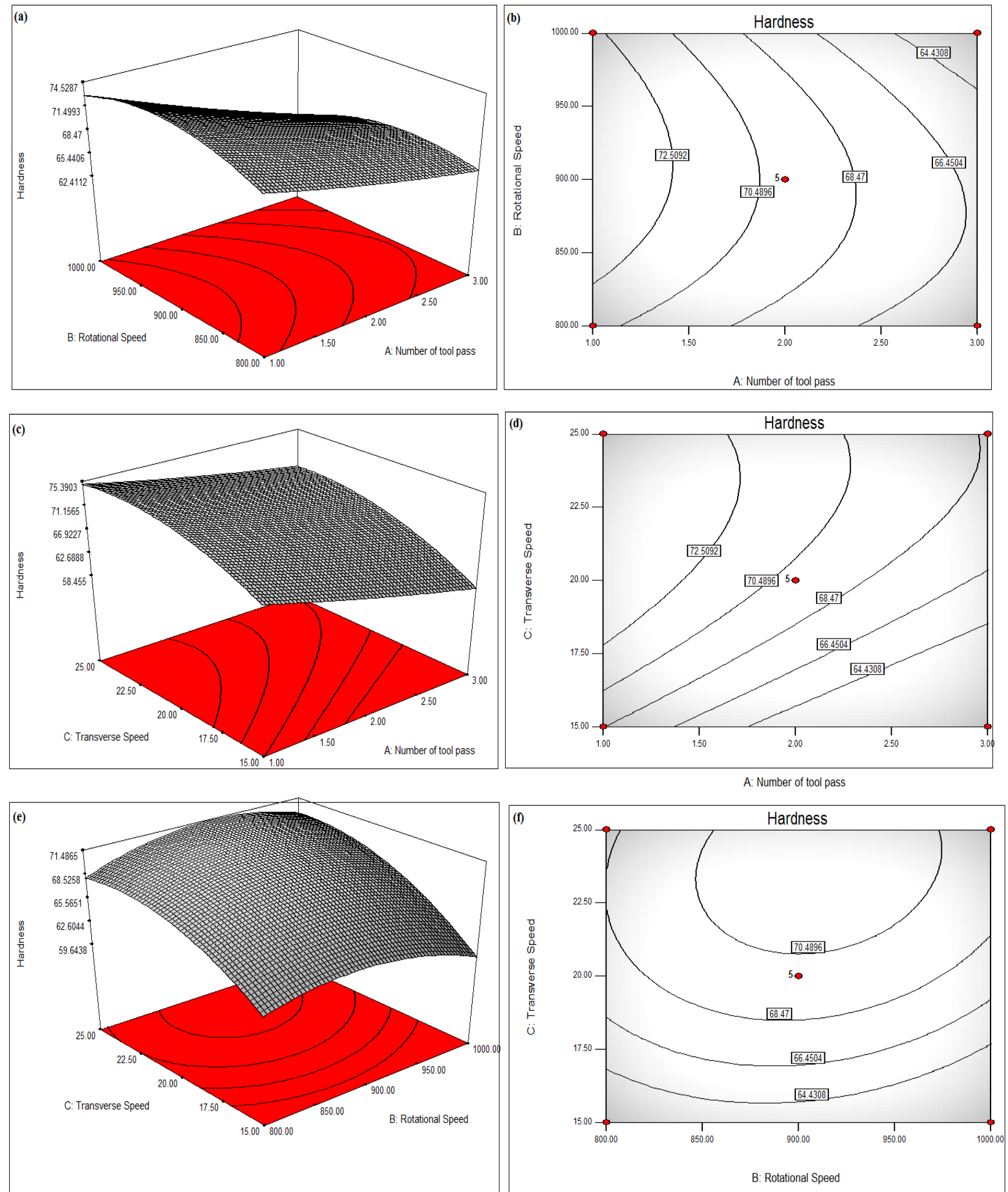

Figure 5. Effect of number of tool pass, tool rotational speed and transverse speed on hardness

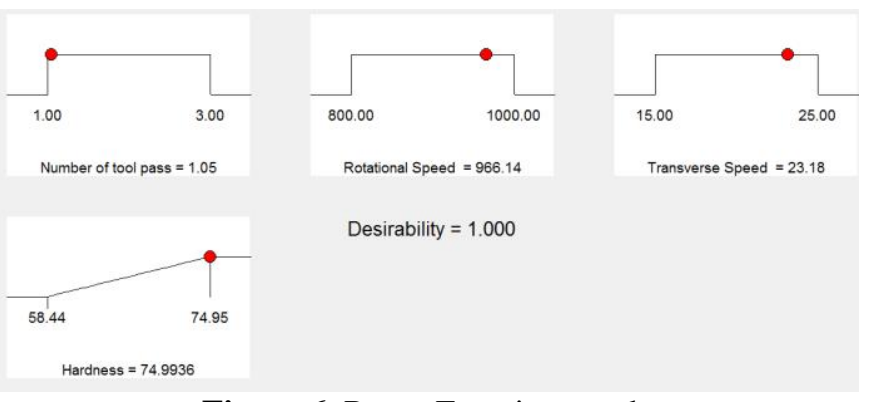

Figure 6. Ramp Function graph

\subsection{XRD behaviour of composite}

Figure 7 shows the XRD analysis of composite developed at the optimum combination of FSP parameters. XRD analysis of composite has been carried out to observe the different phases developed in the eggshell and $\mathrm{SiC}$ reinforced composite material. The XRD analysis of the $\mathrm{Al} /$ carbonized eggshells/SiC composite shows the presence of $\mathrm{CaCO}_{3}, \mathrm{Al}$, $\mathrm{SiC}$ and $\mathrm{CaSiO}_{3}$ phases. 


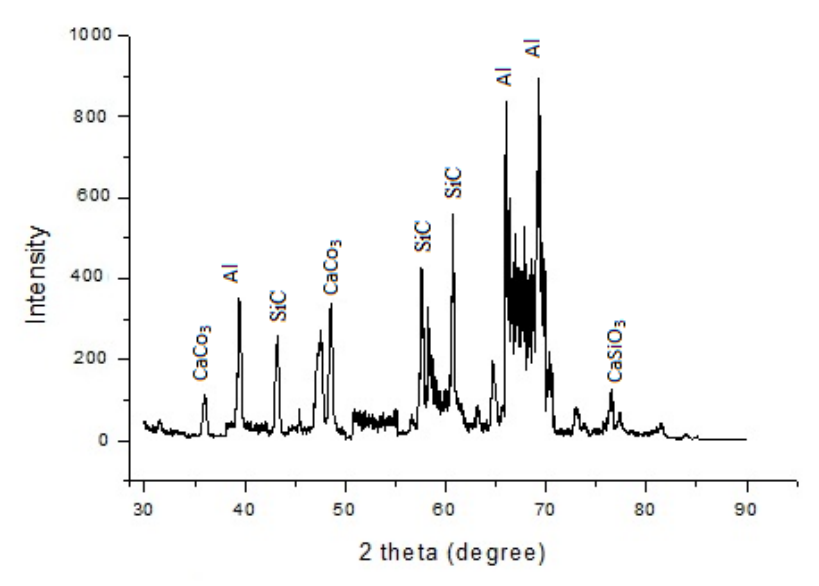

Figure 7. XRD of Al/Eggshell/SiC composite developed at the optimum combination of FSP parameters

\section{CONCLUSIONS}

Current work is all about minimizing the pollution generated by the food industries by utilizing the eggshell wastes as a primary reinforcement particle. The secondary reinforcement particle being $\mathrm{SiC}$ (Silicon Carbide). The main objective of this work is to obtain an enhanced value of Hardness of the final composite. Concerning this, the parameters of FSP i.e., rotational speed and transverse speed have been optimized through the Box-Behnken Design approach. The optimized values of FSP parameters came out to be as $966.14 \mathrm{rpm}$ of rotational speed and $23.18 \mathrm{~mm} / \mathrm{min}$ as transverse speed value in a single pass of tool. After optimizing these parameters the hardness of the developed composite enhanced by about $6409 \%$ and its value came out to be $72.2 \mathrm{BHN}$. Tensile strength of the composite developed at an optimum combination of parameters was found to be 194.48 MPa. XRD of the developed composite has been also identified to observe the different phases of the composite. The XRD analysis of the $\mathrm{Al} /$ carbonized eggshells/ $\mathrm{SiC}$ composite showed the presence of $\mathrm{CaCO}_{3}, \mathrm{Al}, \mathrm{SiC}$ and $\mathrm{CaSiO}_{3}$ phases.

\section{REFERENCES}

[1] Kumar, S., Dwivedi, S.P., Dwivedi, V.K. (2020). Synthesis and characterization of ball-milled eggshell and $\mathrm{Al}_{2} \mathrm{O}_{3}$ reinforced hybrid green composite material. Journal of Metals, Materials and Minerals, 30(2): 67-75.

[2] Dwivedi, S.P., Srivastava, A.K, Maurya, N.K., Sahu, R. (2020). Microstructure and mechanical behaviour of $\mathrm{Al} / \mathrm{SiC} /$ Agro-Waste RHA hybrid metal matrix composite. Revue des Composites et des Matériaux Avancés, 30(1): 43-47. http://dx.doi.org/10.18280/rcma.300107

[3] Dwivedi, S.P., Sharma, P., Saxena, A. (2020). Utilization of waste spent alumina catalyst and agro-waste rice husk ash as reinforcement materials with scrap aluminium alloy wheel matrix. Proc IMechE Part E: J Process Mechanical Engineering ImechE, 234(6): 543-552. https://doi.org/10.1177/0954408920930634

[4] Dwivedi, S.P., Dixit, A., Bajaj, R. (2019). Development of bio-composite material by utilizing chrome containing leather waste with $\mathrm{Al}_{2} \mathrm{O}_{3}$ ceramic particles. Mater. Res. Express, 6(10): 105105.

[5] Mandal, A., Farhan, M.K., Sastry, T.P. (2016). Effect of reinforced $\mathrm{Al}_{2} \mathrm{O}_{3}$ nanoparticles on collagen nanobiocomposite from chrome-containing leather waste for biomedical applications. Clean Techn Environ, 18: 765-773. http://dx.doi.org/10.1007/s10098-015-1045-3

[6] Dwivedi, S.P., Srivastava, A.K. (2020). Utilization of chrome containing leather waste in development of aluminium based green composite material. International Journal of Precision Engineering and ManufacturingGreen Technology, 7: 781-790. http://dx.doi.org/10.1007/s40684-019-00179-1

[7] Dwivedi, S.P., Saxena, A. (2020). Extraction of collagen powder from chrome containing leather waste and its composites with alumina employing different casting techniques. Materials Chemistry and Physics, 253: 123274.

https://doi.org/10.1016/j.matchemphys.2020.123274

[8] Dwivedi, S.P. (2020). Effect of ball-milled $\mathrm{MgO}$ and Si3N4 addition on the physical, mechanical and thermal behaviour of aluminium based composite developed by hybrid casting technique. International Journal of Cast Metals $\quad$ Research, 33(1): 35-49. http://dx.doi.org/10.1080/13640461.2020.1744370

[9] Dwivedi, S.P., Mishra, V.R. (2019). Physico-chemical, mechanical and thermal behaviour of agro-waste RHAreinforced green emerging composite material. Arabian Journal for Science and Engineering, 44: 8129-8142. http://dx.doi.org/10.1007/s13369-019-03784-z

[10] Maurya, N.K., Maurya, M., Srivastava, A.K., Dwivedi, S.P., Kumar, A., Chauhan, S. (2020). Investigation of mechanical properties of Al 6061/SiC composite prepared through stir casting technique. Materials Today: Proceedings, 25(4): 755-758. https://doi.org/10.1016/j.matpr.2019.09.003

[11] Singh, C.V., Pachauri, P., Dwivedi, S.P., Sharma, S., Singari, R.M. (2019). Formation of functionally graded hybrid composite materials with $\mathrm{Al}_{2} \mathrm{O}_{3}$ and RHA reinforcements using friction stir process. Australian Journal of Mechanical Engineering. https://doi.org/10.1080/14484846.2019.1679583

[12] Rajendran, C., Srinivasan, K., Balasubramanian, V. (2019). Effect of post weld heat treatment on strength and microstructure of friction stir welded lap joints of AA2014-T6 aluminum alloy. Metal Science and Heat Treatment, 61: 305-310. http://dx.doi.org/10.1007/s11041-019-00421-2

[13] Bagheri, B., Abbasi, M. (2020). Development of AZ91/SiC surface composite by FSP: effect of vibration and process parameters on microstructure and mechanical characteristics. Adv. Manuf, 8: 82-96. http://dx.doi.org/10.1007/s40436-019-00288-9

[14] Ikubanni Peter, P., Oki, M., Adeleke Adekunle, A. (2020). A review of ceramic/bio-based hybrid reinforced aluminium matrix composites. Cogent Engineering, 7(1). https://doi.org/10.1080/23311916.2020.1727167

[15] Senapati, A., Manas, V., Singh, A., Dash, S., Sahoo, P. (2016). A comparative investigation on physical and mechanical properties of mmc reinforced with waste materials. International Journal of Research in Engineering and Technology, 5(1): 172-17.

[16] Bodunrin, M., Alaneme, K., Chown, L. (2015). Aluminium matrix hybrid composites: A review of reinforcement philosophies; mechanical, corrosionand tribological characteristics. Journal of Materials Research and Technology, 4(4): 434-445. 
https://doi.org/10.1016/j.jmrt.2015.05.003

[17] Velosa, J., Fangueir, R., Martins, N., Fernandes, M., Soutinho, F. (2013). Waste fiber reinforced composite materials: production and mechanical properties. Materials Science Forum, 730-732: 665-670. http://dx.doi.org/10.4028/www.scientific.net/MSF.730732.665

[18] Yuvaraj, N., Aravindan, S., Vipin. (2015). Fabrication of Al5083/B4C surface composite by friction stir processing and its tribological characterization. Journal of Material Research and Technology, 4(4): 398. http://dx.doi.org/10.1016/j.jmrt.2015.02.006

[19] Saini, N., Dwivedi, D.K., Jain, P.K., Singh, H. (2015). Surface modification of cast Al-17\%Si alloys using friction stir processing. Procedia Engineering, 100: 15221531. http://dx.doi.org/10.1016/j.proeng.2015.01.524

[20] Rouhi, S., Mostafapour, V., Ashjari, M. (2015). Effects of welding environment on microstructure and mechanical properties of friction stir welded AZ91C magnesium alloy joints. Science and Technology of
Welding and Joining, 21(1): 25. https://doi.org/10.1179/1362171815Y.0000000058

[21] Yang, K., Li, W.Y., Niu, P.L., Yang, X.W., Xu, Y.X. (2018). Cold sprayed $\mathrm{AA} 2024 / \mathrm{Al}_{2} \mathrm{O}_{3}$ metal matrix composites improved by friction stir processing: Microstructure characterization, mechanical performance and strengthening mechanisms. J. Alloy. Compd., 736: 115-123. https://doi.org/10.1016/j.jallcom.2017.11.132

[22] Fernandez, J.B., Macias, E.J., Muro, J., Caputi, L.S., Miriello, D., De Luca, R., Roca, A.S., Fals, H.D.C. (2018). Tribological behavior of AA1050H24-graphene nanocomposite obtained by friction stir processing. Metals, 8(2): 113. http://dx.doi.org/10.3390/met8020113

[23] Yang, R., Zhang, Z.Y., Zhao, Y.T., Chen, G., Guo, Y.H., Liu, M.P., Zhang, J. (2015). Effect of multi-pass friction stir processing on microstructure and mechanical properties of Al3Ti/A356 composites. Mater. Charact., 106(1):

62-69. 